Yüzüncü Yil Üniversitesi
Tarim Bilimleri Dergisi

Araştırma Makalesi (Research Article)

\title{
Hizan (Bitlis) Koşullarında Yetiştirilen Üzüm Çeşitlerinin Klorofil Miktarları ve Stoma Yoğunluklarının Belirlenmesi
}

\section{Adnan DOĞAN ${ }^{1}$, Cüneyt UYAK ${ }^{* 2}$, Anıl AKÇAY ${ }^{3}$, Nurhan KESKİN ${ }^{4}$, Ruhan İ.G. ŞENSOY $^{5}$, Ferit ÇELIK $^{6}$, Birhan KUNTER ${ }^{7}$, Şeyda ÇAVUŞOĞLU ${ }^{8}$, Koray ÖZRENK ${ }^{9}$}

\author{
1,2,3,4,5,6,8 Van Yüzüncü Y11 Üniversitesi, Ziraat Fakültesi, Bahçe Bitkileri Bölümü, 65090, Van, Türkiye \\ ${ }^{7}$ Ankara Üniversitesi, Ziraat Fakültesi, Bahçe Bitkileri Bölümü, 06560, Ankara, Türkiye \\ ${ }^{9}$ Siirt Üniversitesi, Ziraat Fakültesi, Bahçe Bitkileri Bölümü, 56100, Siirt, Türkiye \\ ${ }^{1}$ https://orcid.org/0000-0002-8623-0629 ${ }^{2}$ https://orcid.org/0000-0002-6101-6845 ${ }^{3}$ https://orcid.org/0000 -0002-8046-1186 \\ ${ }^{4}$ https://orcid.org/0000-0003-2332-1459 ${ }^{5}$ https://orcid.org/0000-0002-2379-0688 ${ }^{6}$ https://orcid.org/0000-0001-9089-2468 \\ ${ }^{7}$ https://orcid.org/0000-0001-7112-1908 ${ }^{8}$ https://orcid.org/0000-0001-8797-6687 ${ }^{9}$ https://orcid.org/0000-0002-6692-2337 \\ *Sorumlu yazar e-posta: cuneytuyak@gmail.com
}

\section{Makale Bilgileri}

Geliş: 04.03.2020

Kabul: 15.08.2020

Online Yayınlanma 31.12.2020

DOI: $10.29133 /$ yyutbd.698508

\section{Anahtar kelimeler}

Stoma yoğunluğu,

SPAD,

Klorofil,

Üzüm çeşidi.
Öz: $\mathrm{Bu}$ çalışma, stoma yoğunluğu ve boyutları üzerine çeşidin, kullanılan yöntemlerin (kalıp alma/saydamlaştırma), yaprakların alınma konumlarının (gölge/güneş) ve yaprak yüzeyinin farklı bölgelerinden örnek almanın (uç, orta, dip) etkilerini ortaya koymak ve çeşitlerin toplam klorofil, klorofil a, klorofil b, karotenoid miktarları ile SPAD değerlerini tespit etmek amacıyla 2017 yılında Hizan yöresinde yetiştirilen 28 yerel üzüm çeşidi üzerinde yürütülmüştür. Çalışmada çeşit, yöntem ve yaprağın alındığı konumun stoma yoğunluğu üzerine olan etkisinin önemli olduğu ancak yaprak yüzeyinin farklı bölgelerinden örnek almanın stoma yoğunluğu üzerine etkisinin önemsiz olduğu tespit edilmiştir. Aynı şekilde, çeşit ve yöntemin stoma boyutları üzerine olan etkilerinin önemli olduğu ancak yaprağın alınma konumunun ve yaprak yüzeyinin farklı bölgelerinden örnek almanın stoma boyutları üzerine olan etkisinin önemsiz olduğu belirlenmiştir. Tüylü ve yüzeyi pürüzlü asma yapraklarında daha iyi bir stomatal değerlendirmenin yapılmasında saydamlaştırma yönteminin tercih edilmesi gerektiği kanaatine varılmıştır. Çalışmada çeşidin toplam klorofil, klorofil a, klorofil b ve karotenoid miktarları ile SPAD değerleri üzerine olan etkisinin önemli olduğu ve çeşitler arasında bu değerler bakımından önemli farkl1lıklar olduğu belirlenmiştir. Güneşte olan yaprakların SPAD değerlerinin gölgede olan yapraklara göre daha yüksek olduğu gözlemlenmiştir.

\section{Determination of Chlorophyll Amounts and Stoma Densities of Grape Cultivars Grown in Hizan (Bitlis) Conditions}

\section{Article Info}

Received: 04.03.2020

Accepted: 15.08 .2020

Online Published 31.12.2020

DOI: $10.29133 /$ yyutbd.698508

Keywords

Stoma density, SPAD,
Abstract: In order to reveal effects of cultivar, methods used (nail polish and transparented leaf method), picking positions of the leaves (shade / sun) and sampling from different parts of the leaf surface (tip, middle, bottom) on stoma density and sizes and determine total chlorophyll, chlorophyll a, chlorophyll b, carotenoid amounts and SPAD values of the cultivars, this research was carried out on 28 local grape cultivars grown in Hizan province in 2017. In the study, it was determined that the effect of the cultivar, method used and picking position of the leaf on the stoma density was important, but the effect of sampling from different parts of the leaf surface on the stoma density was insignificant. Similarly, it was determined that the effect of the cultivar, method used and on the stoma sizes was 
Chlorophyll, Grape cultivar. important, but the effect of picking position of the leaf and sampling from different parts of the leaf surface on the stoma sizes was insignificant. It was concluded that the transparented leaf method should be preferred in making better stomatal observation in the hairy and rough grapevine leaves. In the study, it was determined that the effect of the cultivar on total chlorophyll, chlorophyll a, chlorophyll b and carotenoid amounts and SPAD values was important and there were important differences between cultivars in terms of these values. It was observed that the SPAD values of the leaves in the sun were higher than the leaves in the shade.

\section{Giriş}

Ekolojik dengenin doğal unsuru olan bitkiler, fotosentez sayesinde canlı yaşamının sürdürülmesi için gerekli olan besin ve oksijeni üretirken, transpirasyon sayesinde de hem kendi fizyolojik faaliyetlerinin hem de doğadaki su döngüsünün devamlılığını sağlarlar. Canlı yaşamının devamlılı̆̆ını sağlayan bu iki fizyolojik faaliyetin meydana gelmesinde stomalar ve klorofil en önemli rolleri üstlenmişlerdir. Yapraklarda bulunan stomalar yaprak ve atmosfer arasındaki karbondioksit $\left(\mathrm{CO}_{2}\right)$, oksijen $\left(\mathrm{O}_{2}\right)$ ve su buharı alışverişini sağlayarak transpirasyon ve fotosentezi yönlendirmektedirler. Bitki-su ilişkisi bitkilerin verimliliği, ürün kalitesi, adaptasyon yetenekleri ve fizyolojik faaliyetleri üzerine etkili olan faktörlerden biridir. Bitkilerde buhar halindeki su kaybının \%85-90'nı stomalardan gerçekleşmekte (Yentürk, 1984) ve stomaların yoğunluk ve boyutları bitkilerin fotosentez ve transpirasyon gibi fizyolojik olayları, bitki-su ilişkilerini ve değişik çevre koşullarına adaptasyon yeteneklerini önemli bir şekilde etkilemektedir (Loveys ve Kriedeman, 1973; Ohsinu ve ark., 2007; Yousufzai ve ark., 2009; Arminian ve ark., 2010; Sarwar ve ark., 2013; Küçükyumruk ve ark., 2015). Bitkilerdeki stoma yoğunlukları ve boyutları tür ve çeşit özelliklerine, çevre ve bakım koşulları ile vejetatif gelişme oranına göre değişim gösterebilmektedir (Iotsova-Baurenska, 1975; Rana ve ark., 1990, Misırlı ve Aksoy, 1994; Çağlar ve ark., 2004; Ilgın ve Çağlar, 2009). Asma tür ve çeşitlerinde stoma yoğunlukları ve boyutları ile bunlar üzerine etkili olan faktörleri belirlemek amaciyla çok sayıda çalışma yapılmıştır (Marasalı ve Aktekin, 2003; Gökbayrak ve ark., 2008; Gargın, 2009; Rogiers ve ark., 2011; Bekişli, 2014; Durmaz, 2014; İşçi ve ark., 2015; Tetik ve Dardeniz, 2016; Atik ve Dardeniz, 2018; Aras ve Eşitken, 2019). Asmalarda fotosentez, su kaybı, adaptasyon, gelişme, verim ve kalite ile stoma yoğunluğu ve boyutları arasındaki ilişkilerin belirlenmesi yetiştiricilik açısından oldukça önemlidir.

Fotosentezde görev yapan en aktif pigmentler klorofillerdir. Klorofiller fotosentez sırasında 1şık enerjisinin absorbe edilmesinde ve fotosentezin değişik aşamalarında katalizör görevi yaparlar (Kaçar ve ark., 2006). Yapraklardaki klorofil miktarı hayat formu, mevsim ve 1şık koşulları gibi birçok içsel ve dışsal faktörün kombine etkisi ile geniş değişkenlik göstermektedir (Kutbay ve Kılınç, 1992). Yapraklardaki klorofil miktarı ile yaprakta tutulan ışı miktarı arasında sıkı bir ilişki olduğu ve bu nedenle klorofil miktarının doğrudan fotosentez yoğunluğu ve karbonhidrat üretimine etki ettiği bildirilmiştir (Curran ve ark., 1990; Kutbay ve Kılınç, 1992). Bitkilerde klorofil içeriği fizyolojik faaliyetlerin, bitki stresinin ve besin elementi eksikliklerinin önemli bir göstergesidir (Penuelas ve ark., 1995; Marschner, 1995). Asma tür ve çeşitlerinde klorofil miktarlarının belirlenmesi amacıyla birçok çalışma yürütülmüştür (Gargın, 2011; Dardeniz ve ark., 2012; Uyak ve ark., 2016). Asma yapraklarındaki klorofil miktarı, kültürel uygulamalara, stres koşullarına, beslenme durumuna ve ekolojik koşullara bağlı olarak değişiklik gösterebilmekte ve dolayısıyla verim ve kaliteyi direkt olarak etkileyebilmektedir (Dardeniz ve ark., 2012).

Bu çalışmanın amacı, Hizan yöresinde yetiştirilen yerel üzüm çeşitlerinde stoma yoğunluğu ve boyutları üzerine çeşidin, kullanılan yöntemlerin (kalıp alma/saydamlaştırma), yaprakların alınma konumlarının (gölge/güneş) ve yaprak yüzeyinin farklı yerlerinden örnek almanın (uç, orta, dip) etkilerini ortaya koymak ayrıca çeşitlerin toplam klorofil, klorofil a, klorofil b, karotenoid miktarları ile SPAD değerlerini tespit etmektir.

\section{Materyal ve Yöntem}

Bu çalışma, 2017-2018 yılları arasında Bitlis ili Hizan ilçesinde yetiştirilen 28 yerel üzüm çeşidi üzerinde yürütülmüştür. Üzüm çeşitleri kendi kökleri üzerinde yetiştirilmekte olup, yöresel isimleri 
şöyledir; Bagıltı Biski Spi, Bagıltı Biski Hışin, Alaki, Kırmızı Tayfi, Tayfi 2, Tayfi 3, Beyaz Güzane, Siyah Güzane, Kırmızı Güzane, Tortor, Miri, Kırmızı Miri, Yediveren, Reşe Aliya, Kırmızı Üzüm, Hüsni Beyaz, Kuş Üzümü, Kuş Üzümü 2, Siyah Sinciri, Beyaz Sinciri, Tilka Piri, Ziraat Üzümü, Siyah Üzüm, Boğa Üzümü, Siyah Kişmiş, Beyaz Bineteti, Bineteti 2, Pekmezlik Üzüm. Üzüm çeşitlerinin değişik yönlere bakan güneş gören ve gölgede olan sürgünlerinin, 4. ile 5. boğumlarından gelişmesini tamamlamış, hastalıksız ve çeşide özgü normal formda olan 20 adet yaprak örneği öğleden sonra saat 16 'da analizler için alınmıştır.

\subsection{Stoma yoğunluğu ve boyutlarının belirlenmesi}

Stoma yoğunluğu ve boyutlarının belirlenmesi amacıyla kalıp alma ve saydamlaştırma yöntemleri kullanılmıştır. Kalıp alma yönteminde; gölgede olan ve güneş gören asma yapraklarının alt taraflarından yaprak ana damarlarının dipten uca doğru her ana damarın sağından ve solundan 1.5 x 3.0 cm'lik alana firça ile ince bir tabaka olacak şekilde şeffaf tırnak cilası uygulanmıştır. Tırnak cilasının iyice kuruduğu görüldükten sonra tırnak cilası sürülen alanların üstü hava boşluğu kalmayacak şekilde şeffaf bantla kapatılmıştır. Sonrasında bant kalıba zarar vermeyecek şekilde hafifçe kaldırılarak mikroskop lamı üzerine hava boşluğu kalmayacak şekilde yapıştırılmıştır. Mikroskopta x40 büyütmede kalıptaki stoma sayıları belirlenmiştir (Eriş ve Soylu 1990). Saydamlaştırma yönteminde ise; gölgede olan ve güneş gören yaprak örneklerinin her birinden yaprağın alt tarafından ana damarlar boyunca sağdan ve soldan çap $2 \mathrm{~cm}$ olan her yapraktan üç adet (dip orta uç kısımlardan) parça alınarak sodyum hipoklorit (\% 2.5) solüsyonu içerisine muşambaya tel zımba ile zımbalanarak yerleştirilmiştir (Durmaz, 2014). Oda sicaklığında $\left(22-23{ }^{\circ} \mathrm{C}\right)$ 22-24 saat tutulan örnekler tamamen şeffaflaştıktan sonra lam üzerine alınan örnekler x 40 büyütmeli mikroskopta sayılmış ve elde edilen değerler hesaplanan katsayısı ile çarpılarak $\mathrm{mm}^{2}$ deki stoma sayısı elde edilmiştir.

\section{2. Klorofil ve karotenoid miktarlarının belirlenmesi}

Klorofil miktarlarının belirlenmesinde SPAD ve Spektrofotometrik yöntemler kullanılmıştır. SPAD yönteminde; her bir üzüm çeşidinin gölgede olan ve güneş gören yapraklarından dört tekerrürlü olarak 100 adet yaprağın ölçümü taşınabilir klorofil metre cihazı (Minolta SPAD-502, Osaka, Japan) ile yapılmıştır. Spektrofotometrik yöntemde ise; SPAD okuması yapılan yapraklardan $0.5 \mathrm{~g}$ taze yaprak örneği alınmış ve \% 80'lik aseton ile homojenize edilerek 50 ml'lik ölçü balonlarına süzülmüştür. Elde edilen süzükteki renk, 645 ve $663 \mathrm{~nm}$ dalga boylarında spektrometrede okunmuş ve aşağıdaki eşitliklerden yararlanarak klorofil miktarları hesaplanmıştır (Withan ve ark., 1971).

$$
\begin{aligned}
& \text { Klf } a(m g / g)=12.7 x(D 663-2.69) x(D 645) x V / 1000 x W \\
& K l f b(\mathrm{mg} / \mathrm{g})=22.91 \times(D 645-4.68) x(D 663) \times V / 1000 x W \\
& \text { Toplam klorofil }=\text { Klorofil } a+\text { Klorofil } b \\
& V=\text { Ekstrakt hacmi }(\mathrm{ml}), W=\text { Ekstrakte edilen bitki ăg } ı r l ı \breve{g} l(g) \text {, } \\
& D=\text { Dalga boyundan elde edilen okuma de ğeri }
\end{aligned}
$$

Aynı ekstraktın $450 \mathrm{~nm}$ dalga boyundaki absorbans değeri kullanılarak toplam karotenoid miktarı aşağıdaki formüle göre hesaplanmıştır (Lichtenthaller, 1987).

$$
\begin{gathered}
\text { Toplam Karotenoit }=4.07 \times A 450-(T K) \\
A=\text { Absorbans değeri }, T K=\text { Toplamklorofil miktarl }
\end{gathered}
$$

Kalıbı çıkarılan ve saydamlaştırılan yapraklardan her çeşit için rastgele seçilen beş adet örnek mikroskopta incelenmiş ve her incelenen örneğin dört tekerrürlü olarak dört ayrı bölgesinde sayım yapılmıştır. Elde edilen değerlere dört tekerrürlü tesadüf parselleri deneme desenine göre varyans analizi 
yapılmıştır. Ortalamalar arsındaki farklılıklar LSD testi ile ortaya konmuştur. Varyans analizi sonucu önemli çıkmayan interaksiyonlara çizelgelerde yer verilmemiştir.

\section{Bulgular ve Tartışma}

\section{1. Üzüm çeşitlerinin stoma yoğunlukları ve boyutlarına ait bulgular}

Çeşitlerin ve yaprakların alınma konumları (gölge/güneş) $(\mathrm{P}<0.001)$ ile kullanılan yöntemlerin (kalıp alma/saydamlaştırma Şekil 1) $(\mathrm{P}<0.05)$ yapraklardaki stoma yoğunluğu üzerine olan etkileri istatistiki olarak önemli bulunmuştur. Yaprak yüzeyinin farklı bölgelerinden (dip, orta, uç) örnek almanın stoma yoğunluğu üzerine etkisinin istatistiki olarak önemli olmadığı tespit edilmiştir. Çeşitlerin ve kullanılan yöntemlerin (kalıp alma/saydamlaştırma) $(\mathrm{P}<0.001)$ stoma boyutları (boy/en) üzerine olan etkileri istatistiki olarak önemli bulunurken; yaprakların alınma konumları (gölge/güneş) ve yaprak yüzeyinin farklı yerlerinden (dip, orta, uç) örnek almanın stoma boyutları üzerine olan etkileri istatistiki olarak önemsiz bulunmuştur (Çizelge 1).

Çizelge 1. Stoma yoğunlukları ve boyutlarına ilişkin varyans analiz sonuçları

\begin{tabular}{|c|c|c|c|c|}
\hline \multicolumn{5}{|c|}{ Stoma yoğunluklarına ilişkin varyans analizi } \\
\hline Varyasyon kaynağı & S.D. & K.T. & K.O. & F-Değeri \\
\hline A: Çeşit & 27 & 317739. & 11768.1 & $148.41 * * *$ \\
\hline B: Kalıp alma/ Saydamlaştırma & 1 & 2209.02 & 2209.02 & $27.86 * * *$ \\
\hline C: Gölge / Güneş & 1 & 478378. & 478378. & $6032.86 * * *$ \\
\hline $\begin{array}{l}\text { D: Dip / Orta / Uç } \\
\text { İnteraksiyonlar }\end{array}$ & 2 & 690.821 & 345.411 & $4.36 *$ \\
\hline $\mathrm{AB}$ & 27 & 49532.7 & 1834.55 & $23.14 * * *$ \\
\hline $\mathrm{AC}$ & 27 & 27402.9 & 1014.92 & $12.80 * * *$ \\
\hline $\mathrm{AD}$ & 27 & 13073.6 & 484.209 & $6.11 * * *$ \\
\hline Hata & 304 & 908474. & 11768.1 & 27.86 \\
\hline Toplam & 335 & 317739. & & \\
\hline & \multicolumn{4}{|c|}{ Stoma boylarına ilişkin varyans analizi } \\
\hline Varyasyon Kaynağı & S.D. & K.T. & K.O. & F-Değeri \\
\hline A: Çeşit & 27 & 4796.76 & 177.658 & $14.94 * * *$ \\
\hline B: Kalıp alma / Saydamlaştırma & 1 & 191.012 & 191.012 & $16.06 * * *$ \\
\hline C: Gölge / Güneş & 1 & 14.3745 & 14.3745 & 1.21 Ö.D. \\
\hline D: Dip / Orta / Uc & 2 & 5.10264 & 2.55132 & 0.21 Ö.D. \\
\hline İnteraksiyonlar & & & & \\
\hline $\mathrm{AB}$ & 27 & 789.887 & 29.2551 & $2.46 * *$ \\
\hline $\mathrm{AC}$ & 27 & 1126.34 & 41.7162 & $3.51 * * *$ \\
\hline $\mathrm{AD}$ & 54 & 960.21 & 17.7817 & $1.50 *$ \\
\hline $\mathrm{ABC}$ & 27 & 579.486 & 21.4624 & $1.80 *$ \\
\hline Hata & 1344 & 109457. & 360.055 & \\
\hline Toplam & 1679 & 908474. & & \\
\hline \multicolumn{5}{|c|}{ Stoma enlerine ilişkin varyans analizi } \\
\hline Varyasyon Kaynağ 1 & S.D. & K.T. & K.O. & F-Değeri \\
\hline A: Çeşit & 27 & 1595.75 & 59.1018 & $7.90 * * *$ \\
\hline B: Kalıp alma / Saydamlaştırma & 1 & 166.358 & 166.358 & $22.23 * * *$ \\
\hline C: Gölge / Güneş & 1 & 8.32748 & 8.32748 & 1.11 Ö.D. \\
\hline $\begin{array}{l}\text { D: Dip / Orta / Uç } \\
\text { İnteraksiyonlar }\end{array}$ & 2 & 3.81112 & 1.90556 & 0.25 Ö.D. \\
\hline $\mathrm{AB}$ & 27 & 661.972 & 24.5175 & $3.28 * * *$ \\
\hline $\mathrm{AD}$ & 54 & 551.188 & 10.2072 & $1.36 *$ \\
\hline $\mathrm{ACD}$ & 54 & 571.91 & 10.5909 & $1.42 *$ \\
\hline Hata & 1344 & 10058.2 & 7.48378 & \\
\hline Toplam & 1679 & 15051.9 & & \\
\hline
\end{tabular}

***: $(\mathrm{p}<0.001) ; * *:(\mathrm{p}<0.01) ; *:(\mathrm{p}<0.05)$; Ö.D.: Önemli Değil 
İnteraksiyonlardan A (çeşit) x B (kalıp alma/saydamlaştırma) $(\mathrm{P}<0.01)$, A (çeşit) x C (gölge/güneş) $(\mathrm{P}<0.001)$, A (çeşit) $\mathrm{x} \quad \mathrm{D} \quad($ dip/orta/uç) $\quad(\mathrm{P}<0.05)$ ve $\mathrm{A}$ (Çeşit) $\mathrm{x} \quad \mathrm{B}$ (kalıp alma/saydamlaştırma) x $\mathrm{C}$ (gölge/güneş) $(\mathrm{P}<0.05)$ interaksiyonlarının stoma boyları üzerine olan etkileri istatistiki olarak önemli bulunmuştur. A (çeşit) x B (kalıp alma/saydamlaştırma) $(\mathrm{P}<0.001)$, A (çeşit) $\mathrm{x}$ $\mathrm{D}$ (dip/orta/uç) $(\mathrm{P}<0.05)$, A (çeşit) x C (gölge/güneş) x D (dip/orta/uç) $(\mathrm{P}<0.05)$ interaksiyonlarının stoma enleri üzerine olan etkilerinin istatistiki olarak önemli olduğu belirlenmiştir (Çizelge 1).

Yapraklardaki stoma yoğunlukları ve boyutları açısından uygulanan metotlar (kalıp alma ve saydamlaştırma) göz ardı edilerek yapılan analizde çeşitler arasında istatistiki olarak farklılıklar olduğu gözlemlenmiştir. En yüksek stoma yoğunlukları Pekmezlik (269.2 adet $\left./ \mathrm{mm}^{2}\right)$ ve Beyaz Binetati $(268,4$ adet $\left./ \mathrm{mm}^{2}\right)$ çeşitlerinde, en düşük stoma yoğunluğu ise Bagıltı Bisti Sipi $\left(150.0\right.$ adet $\left./ \mathrm{mm}^{2}\right)$ çeşidinde belirlenmiştir (Çizelge 2).

Çizelge 2. Çeşitlere göre yapraklarda saptanan stoma yoğunlukları ve boyutları

\begin{tabular}{|c|c|c|c|}
\hline Çeşit & Stoma yoğunluğu (adet $/ \mathrm{mm}^{2}$ ) & Stoma boyu $(\mu \mathrm{m})$ & Stoma eni $(\mu \mathrm{m})$ \\
\hline Tortor & $252.5 \pm 70.500^{b^{*}}$ & $26.6 \pm 3.75^{b-d}$ & $17.5 \pm 3.57^{\mathrm{c}-\mathrm{f}}$ \\
\hline Hüsni Beyaz & $185.0 \pm 31.43^{\mathrm{k}-\mathrm{m}}$ & $25.8 \pm 3.63^{\mathrm{d}-\mathrm{g}}$ & $17.3 \pm 2.44^{\mathrm{d}-\mathrm{g}}$ \\
\hline Siyah Sinciri & $213.3 \pm 47.69^{c-g}$ & $25.7 \pm 3.73^{\mathrm{d}-\mathrm{g}}$ & $17.4 \pm 3.01^{\mathrm{d}-\mathrm{g}}$ \\
\hline Beyaz Sinciri & $159.6 \pm 44.05^{\text {rs }}$ & $25.1 \pm 3.70^{\text {f-h }}$ & $17.3 \pm 3.10^{\mathrm{d}-\mathrm{g}}$ \\
\hline Tilka Piri & $190.0 \pm 31.24^{\mathrm{i}-\mathrm{k}}$ & $23.8 \pm 3.21 \mathrm{ij}$ & $17.0 \pm 3.04^{\mathrm{e}-\mathrm{h}}$ \\
\hline Ziraat Üzümü & $222.0 \pm 41.49^{\mathrm{cd}}$ & $27.4 \pm 4.38^{b}$ & $19.5 \pm 2.69^{\text {a }}$ \\
\hline Beyaz Güzane & $211.5 \pm 41.74^{\mathrm{d}-\mathrm{h}}$ & $25.5 \pm 4.18^{\mathrm{d}-\mathrm{g}}$ & $17.6 \pm 3.41^{\mathrm{c}-\mathrm{f}}$ \\
\hline Kırmızı Tayifi & $216.3 \pm 46.01^{c-f}$ & $26.4 \pm 4.15$ b-e & $17.7 \pm 2.50^{\mathrm{c}-\mathrm{f}}$ \\
\hline Tayifi-2 & $218.3 \pm 34.69^{\mathrm{c}-\mathrm{e}}$ & $22.4 \pm 3.53^{k}$ & $15.6 \pm 2.24^{\mathrm{i}}$ \\
\hline Tayifi-3 & $180.3 \pm 44.77^{\text {l-n }}$ & $26.0 \pm 4.32^{\mathrm{c}-\mathrm{g}}$ & $17.7 \pm 3.05^{\mathrm{c}-\mathrm{f}}$ \\
\hline Yediveren & $199.1 \pm 40.50^{g-j}$ & $26.4 \pm 3.73^{b-e}$ & $16.3 \pm 3.18 \mathrm{hi}$ \\
\hline Alaki & $267.6 \pm 53.75^{\mathrm{ab}}$ & $24.8 \pm 3.30^{g-i}$ & $17.0 \pm 3.39^{\mathrm{f}-\mathrm{h}}$ \\
\hline Siyah Üzüm & $169.5 \pm 35.16 \mathrm{pr}$ & $29.4 \pm 4.39^{a}$ & $17.7 \pm 3.13^{\mathrm{c}-\mathrm{f}}$ \\
\hline Bagıltı Bisti Sipi & $150.0 \pm 38.40^{\mathrm{s}}$ & $30.1 \pm 4.78^{\text {a }}$ & $19.7 \pm 3.58^{\text {a }}$ \\
\hline Bagılltı Bisti Hışin & $206.5 \pm 49.62^{\text {e-h }}$ & $25.2 \pm 3.16^{\mathrm{e}-\mathrm{h}}$ & $16.4 \pm 1.94^{\mathrm{g}-\mathrm{i}}$ \\
\hline Siyah Kişmiş & $173.4 \pm 46.05^{\mathrm{m}-\mathrm{p}}$ & $26.7 \pm 3.25$ bcd & $19.1 \pm 2.31^{\mathrm{ab}}$ \\
\hline Boğa Üzümü & $202.8 \pm 34.85^{f-i}$ & $23.1 \pm 3.40^{\mathrm{jk}}$ & $16.4 \pm 3.02^{g-i}$ \\
\hline Kırmızı Üzüm & $227.8 \pm 29.10^{\mathrm{c}}$ & $25.5 \pm 2.94^{\mathrm{d}-\mathrm{g}}$ & $17.6 \pm 2.40^{\mathrm{c}-\mathrm{f}}$ \\
\hline Miri & $205.8 \pm 31.92^{\text {e-h }}$ & $26.8 \pm 2.93^{b-d}$ & $16.5 \pm 2.65^{\mathrm{f}-\mathrm{i}}$ \\
\hline Kırmızı Miri & $215.8 \pm 50.08^{c-f}$ & $25.8 \pm 3.70^{\mathrm{d}-\mathrm{g}}$ & $17.6 \pm 3.16^{\mathrm{c}-\mathrm{f}}$ \\
\hline Kuş Üzümü & $189.1 \pm 38.60^{\mathrm{i}-\mathrm{k}}$ & $29.3 \pm 3.75^{\mathrm{a}}$ & $18.2 \pm 2.60^{b-d}$ \\
\hline Kuş Üzümü-2 & $168.5 \pm 38.23 \mathrm{pr}$ & $27.6 \pm 4.17^{b}$ & $17.9 \pm 2.21^{\mathrm{c}-\mathrm{f}}$ \\
\hline Reşa Aliya & $217.9 \pm 39.93^{c-f}$ & $25.5 \pm 2.94^{\mathrm{d}-\mathrm{g}}$ & $18.4 \pm 2.33$ bc \\
\hline Kırmızı Güzane & $215.7 \pm 32.20^{\mathrm{c}-\mathrm{f}}$ & $26.7 \pm 4.00^{b-d}$ & $19.1 \pm 3.33$ ab \\
\hline Siyah Güzane & $197.7 \pm 57.08^{h-j}$ & $26.3 \pm 3.73^{b-f}$ & $17.9 \pm 2.63^{\text {c-e }}$ \\
\hline Beyaz Binetati & $268.4 \pm 48.90^{\mathrm{a}}$ & $25.6 \pm 4.85^{\mathrm{d}-\mathrm{g}}$ & $18.2 \pm 2.94^{b-d}$ \\
\hline Binetati-2 & $228.0 \pm 43.22^{\mathrm{c}}$ & $27.2 \pm 3.12^{\mathrm{bc}}$ & $17.8 \pm 2.87^{c-f}$ \\
\hline Pekmezlik & $269.2 \pm 57.01^{\mathrm{a}}$ & $24.1 \pm 3.93^{h-j}$ & $16.2 \pm 2.17 \mathrm{hi}$ \\
\hline Ortalama & 207.9 & 26.1 & 17.6 \\
\hline Maksimum & 269,2 & 30.1 & 19.7 \\
\hline Minimum & 150,0 & 22.4 & 15.6 \\
\hline
\end{tabular}

*: Aynı sütunda farklı harflerle gösterilen ortalamalar arasındaki fark önemlidir (LSD: \%5).

Vitis tür ve çeşitleri arasında yapraklardaki stoma yoğunlukları ve boyutları açısından önemli farklılıkların olduğu birçok araştırıcı tarafından ifade edilmiştir. Nitekim asma yapraklarındaki stoma yoğunluklarını During (1980), 173.6-349.3 adet $/ \mathrm{mm}^{2}$; Eriş ve Soylu (1990), 129-254 adet $/ \mathrm{mm}^{2}$; Gargın (2009), 127-153.8 adet $/ \mathrm{mm}^{2}$; Uyak ve ark. (2016), 128.20-192.30 adet $/ \mathrm{mm}^{2}$ değerleri arasında rapor etmişlerdir. En büyük stoma boyu ve eni Bagıltı Bisti Sipi $(30.1 \mu \mathrm{m}$ ve $19.7 \mu \mathrm{m})$, çeşidinde ölçülürken, en düşük stoma boyu ve eni ise Tayfi $2(22.4 \mu \mathrm{m}$ ve $15.6 \mu \mathrm{m})$ çeşidinde ölçülmüsştür (Çizelge 2). Eriş̧ ve Soylu (1990), stoma boylarının 22.6- $28.3 \mu \mathrm{m}$, stoma enlerinin 13.6-18.6 $\mu \mathrm{m}$; Uyak ve ark. (2016), stoma boylarının 20.43-27.82 $\mu \mathrm{m}$, stoma enlerinin ise 13.12-18.36 $\mu \mathrm{m}$ değerleri arasında değiştiğini bildirmişlerdir. Stoma boyutları bakımından en yüksek değerleri alan Bagıltı Bisti Sipi çeşidi en düşük stoma yoğunluğuna sahip olurken, en düşük stoma boyutlarına sahip Tayfi 2 çeşidi ise stoma yoğunluğu 
bakımından en yüksek değeri göstermemiştir. Eriş ve Soylu (1990), stoma yoğunlukları ile stoma boyutları arasındaki korelasyonun önemsiz olduğunu ancak stoma eni ve boyu arasındaki korelasyonun ise önemli olduğunu rapor etmişlerdir.

Çalışmada kullanılan her iki yöntemde de (kalıp alma ve saydamlaştırma) yapraklardaki stoma yoğunluğu ve stoma boyutları açısından çeşitler arasında istatistiki olarak farklılık olduğu tespit edilmiştir. Kalıp alma yönteminde en yüksek stoma yoğunluğu Alaki çeşidinde $\left(281.0 \mathrm{adet} / \mathrm{mm}^{2}\right)$, en büyük stoma boyu ve eni Bagıltı Bisti Sipi çeşidinde (30.6 ve $20.0 \mu \mathrm{m})$ belirlenirken, en düşük stoma yoğunluğu Beyaz Sinciri (146.3 adet $/ \mathrm{mm}^{2}$ ) çeşidinde en düşük stoma boyu ve eni ise Tayfi 2 çeşidinde $(22.8$ ve $15.1 \mu \mathrm{m})$ belirlenmiştir. Saydamlaştırma yönteminde en yüksek stoma yoğunluğu Beyaz Bineteti çeşidinde $\left(289.6\right.$ adet $\left./ \mathrm{mm}^{2}\right)$ en büyük stoma boyu Siyah Üzüm çeşidinde $(29.9 \mu \mathrm{m})$, en büyük stoma eni Siyah Kişmiş çeşidinde $(19.5 \mu \mathrm{m})$ ölçülürken, en düşük stoma yoğunluğu Bagıltı Bisti Sipi çeşidinde (153.1 adet $\left./ \mathrm{mm}^{2}\right)$, en düşük stoma boyu Tayfi 2 çeşidinde $(22.1 \mu \mathrm{m})$, en düşük stoma eni ise Bagıltı Bisti Hışin çeşidinde $(16.0 \mu \mathrm{m})$ ölçülmüsştür. Kalıp alma metodunda stoma yoğunluğu 16 çeşitte, stoma boyu 15 çeşitte, stoma eni ise 11 çeşitte saydamlaştırma metoduna göre daha yüksek bulunurken, saydamlaştırma metodunda ise stoma yoğunluğu 12 çeşitte, stoma boyu 11 çeşitte, stoma eni ise 15 çeşitte kalıp alma metoduna göre daha yüksek bulunmuştur (Çizelge 3). Durmaz (2014), kalıp alma ve saydamlaştırma yöntemlerinin her ikisinde de günește ve gölgede olan yaprakların stoma yoğunluğu açısından hem kültür çeşitleri hem de anaçlar arasında istatistiki olarak farklılık olduğunu bildirmiştir. Aynı araştırıcı güneşte ve gölgede olan yaprakların her ikisinde de hem kültür çeşitlerinde hem de anaçlarda saydamlaştırma yöntemine göre belirlenen stoma yoğunluklarının kalıp alma yöntemine göre daha yüksek olduğunu rapor etmiştir. Stoma boyutları bakımından üzüm çeşitleri arasında farklılıkların olduğunu diğer araştırıcılar tarafından da bildirilmiştir (Eriş ve Soylu, 1990; Uyak ve ark, 2016).

Çalışmada yaprakların alındığı her iki konumda da (gölge/güneş) yapraklardaki stoma yoğunluğu ve stoma boyutları açısından çeşitler arasında istatistiki olarak farklılık olduğu belirlenmiştir. Gölgede ve güneşte olan yapraklarda sırasıyla en yüksek stoma yoğunluğu Beyaz Bineteti (228.7 adet $/ \mathrm{mm}^{2}$ ) ve Pekmezlik (322.9 adet $/ \mathrm{mm}^{2}$ ) çeşitlerinde saptanırken, en düşük stoma yoğunluğu ise her iki konumda da Bagıltı Bisti Sipi (113.9 ve 186.1 adet $/ \mathrm{mm}^{2}$ sırasıyla) çeşidinde saptanmıştır. Tüm çeşitlerde güneşte olan yaprakların stoma yoğunluklarının gölgede olan yapraklara göre daha fazla olduğu tespit edilmiştir (Çizelge 4). Durmaz (2014), güneşte ve gölgede olan yaprakların her ikisinde de stoma yoğunluğu açısından her iki yöntemde de (kalıp alma ve saydamlaştırma) hem kültür çeşitleri hem de anaçlar arasında istatistiki olarak farklılık olduğunu bildirmiş̧ir. Ayrıca, araştırıcı tüm kültür çeşitleri ve anaçlarda güneşte olan yaprakların stoma yoğunluklarının gölgede olan yapraklara göre daha yüksek olduğunu tespit etmiştir. Gölgede ve güneşte olan yaprakların her ikisinde de en büyük stoma boyu Bagıltı Bisti Sipi (gölge $30.3 \mu \mathrm{m}$ ve güneş $29.8 \mu \mathrm{m}$ ) çeşidinde ölçülürken, en düşük stoma boyu ise gölgede olan yapraklarda Boğa üzüm çeşidinde $(22.9 \mu \mathrm{m})$, güneşte olan yapraklarda ise Tayfi 2 çeşidinde $(21.8 \mu \mathrm{m})$ ölçülmüştür. Yapılan araştırmada stoma enlerine ilişkin değerlendirmede gölge/güneş faktörünün tekil olarak incelenen yerel üzüm çeşitlerinde istatistiki anlamda farklılık önemli bulunmamıştır. Fakat yerel üzüm çeşitlerinde arasındaki farklılı̆̆ın $(\mathrm{p}<0.001)$ oldukça önemli olması interaksiyonlardan olan A (çeşit) x C (gölge/güneş) $(\mathrm{P}<0.05)$, A (çeşit) x C (gölge/güneş) x D (dip/orta/uç) $(\mathrm{P}<0.05)$ seviyesinde farklılığa neden olduğu düşünülmektedir. İncelenen 16 çeşitte gölgede olan yaprakların stoma boyları güneşte olan yapraklara göre daha yüksek bulunurken, 12 çeşitte güneşte olan yaprakların stoma boyları gölgede olanlara göre daha yüksek bulunmuştur.

Asmalarda stoma yoğunluğu ve boyutlarının gübreleme (Tompa ve ark., 1976; Boselli ve Scienza, 1983; Ruehl ve Imgraben, 1985), fungusit uygulamaları (Sekera, 1983); anaç ve terbiye sistemi (Düzenli ve Ergenoğlu, 1988; Kara ve Özeker, 1999; İşçi ve ark, 2015; Atik ve Dardeniz, 2018; Çeliktopuz ve ark., 2018), çevre koşullarına ve çeşide (Eriş ve Soylu, 1990) göre değişiklik gösterdiği rapor edilmiştir. 
Çizelge 3. Uygulanan yöntemlere göre (çeşit x kalıp alma/saydamlaştırma) yapraklarda saptanan stoma yoğunlukları ve boyutları

\begin{tabular}{|c|c|c|c|c|c|c|}
\hline \multirow[t]{2}{*}{ Çeşitler } & \multicolumn{2}{|c|}{ Stoma yoğunluğu $\left(\operatorname{adet} / \mathrm{mm}^{2}\right)$} & \multicolumn{2}{|c|}{ Stoma boyu $(\mu \mathrm{m})$} & \multicolumn{2}{|c|}{ Stoma eni $(\mu \mathrm{m})$} \\
\hline & Kalıp alma & Saydamlaştırma & Kalıp alma & Saydamlaştırma & Kalıp alma & Saydamlaştırma \\
\hline Tortor & $230.8 \pm 74.49$ de & $274.3 \pm 65.17^{b}$ & $27.4 \pm 4.33^{a-d}$ & $25.9 \pm 2.98^{\text {a-e }}$ & $18.2 \pm 4.22^{\mathrm{a}-\mathrm{d}}$ & $16.9 \pm 2.67 \mathrm{ab}$ \\
\hline Hüsni Beyaz & $189.9 \pm 32.53 \mathrm{kl}$ & $180.0 \pm 32.51^{\mathrm{pq}}$ & $27.0 \pm 3.76^{\mathrm{a}-\mathrm{d}}$ & $24.6 \pm 3.22$ b-e & $17.1 \pm 2.68^{a-d}$ & $17.5 \pm 2.21^{\mathrm{ab}}$ \\
\hline Siyah Sinciri & $188.4 \pm 38.89 \mathrm{~lm}$ & $238.3 \pm 44.69^{\mathrm{e}}$ & $26.3 \pm 4.20^{b-d}$ & $25.0 \pm 3.14^{\text {b-e }}$ & $17.5 \pm 3.81^{\mathrm{a}-\mathrm{d}}$ & $17.4 \pm 1.99$ ab \\
\hline Beyaz Sinciri & $146.3 \pm 34.56$ q & $172.9 \pm 51.46^{\mathrm{r}}$ & $24.2 \pm 3.54^{\mathrm{d}}$ & $26.0 \pm 3.70^{a-d}$ & $15.7 \pm 2.53^{\mathrm{cd}}$ & $18.8 \pm 2.88^{a b}$ \\
\hline Tilka Piri & $194.1 \pm 22.70^{j k}$ & $186.0 \pm 39.91^{n-p}$ & $23.8 \pm 3.24^{\mathrm{d}}$ & $23.8 \pm 3.24$ de & $17.0 \pm 3.06^{b-d}$ & $17.0 \pm 3.06^{\mathrm{ab}}$ \\
\hline Ziraat Üzümü & $237.9 \pm 48.14^{\mathrm{d}}$ & $206.1 \pm 29.36^{\mathrm{kl}}$ & $27.9 \pm 4.92^{\mathrm{a}-\mathrm{c}}$ & $26.9 \pm 3.77^{\mathrm{a}-\mathrm{c}}$ & $19.7 \pm 3.18$ ab & $19.3 \pm 2.13^{\mathrm{a}}$ \\
\hline Beyaz Güzane & $232.3 \pm 41.94^{\mathrm{d}}$ & $190.3 \pm 32.22 \mathrm{mn}$ & $24.8 \pm 4.46^{\mathrm{d}}$ & $26.2 \pm 3.84^{\mathrm{a}-\mathrm{c}}$ & $16.5 \pm 3.43^{\mathrm{cd}}$ & $18.8 \pm 3.01 \mathrm{ab}$ \\
\hline Kırmızı Tayifi & $203.9 \pm 43.17 \mathrm{hi}$ & $228.7 \pm 49.25^{f}$ & $27.5 \pm 4.25^{\mathrm{a}-\mathrm{c}}$ & $25.4 \pm 3.85^{\text {b-e }}$ & $17.8 \pm 2.36^{\mathrm{a}-\mathrm{d}}$ & $17.7 \pm 2.67 \mathrm{ab}$ \\
\hline Tayifi-2 & $222.7 \pm 35.71^{e}$ & $213.7 \pm 36.42^{j}$ & $22.8 \pm 3.72^{\mathrm{d}}$ & $22.1 \pm 3.36^{\mathrm{e}}$ & $15.1 \pm 2.31^{\mathrm{d}}$ & $16.1 \pm 2.08^{b}$ \\
\hline Tayifi-3 & $175.2 \pm 48.92^{n}$ & $185.3 \pm 44.22$ ор & $27.2 \pm 4.51^{\mathrm{a}-\mathrm{d}}$ & $24.7 \pm 3.78$ b-e & $18.3 \pm 3.64^{\mathrm{a}-\mathrm{c}}$ & $17.1 \pm 2.16^{\mathrm{ab}}$ \\
\hline Yediveren & $195.9 \pm 49.87^{\mathrm{j}}$ & $202.3 \pm 33.09^{1}$ & $26.9 \pm 3.31$ b-d & $25.9 \pm 3.51^{\text {b-e }}$ & $15.3 \pm 1.99^{\mathrm{d}}$ & $17.2 \pm 3.83^{\mathrm{ab}}$ \\
\hline Alaki & $281.0 \pm 57.90^{\mathrm{a}}$ & $254.1 \pm 50.70^{c}$ & $25.0 \pm 3.11^{\mathrm{d}}$ & $24.5 \pm 3.51$ ede & $17.4 \pm 4.07^{\mathrm{a}-\mathrm{d}}$ & $16.5 \pm 2.53^{b}$ \\
\hline Siyah Üzüm & $184.0 \pm 36.58^{\mathrm{m}}$ & $155.0 \pm 29.63^{\mathrm{s}}$ & $28.9 \pm 4.56$ ab & $29.9 \pm 4.21^{\mathrm{a}}$ & $16.6 \pm 3.02^{\mathrm{cd}}$ & $18.8 \pm 2.92 \mathrm{ab}$ \\
\hline Bagıltı Bisti Sipi & $147.0 \pm 42.93$ q & $153.1 \pm 37.14^{\mathrm{s}}$ & $30.6 \pm 4.77^{\mathrm{a}}$ & $29.5 \pm 4.82^{\mathrm{a}}$ & $20.0 \pm 4.27^{\mathrm{a}}$ & $19.3 \pm 2.76^{\mathrm{a}}$ \\
\hline Bagılttı Bisti Hıșin & $201.2 \pm 56.10^{\mathrm{i}}$ & $211.8 \pm 46.94^{j}$ & $26.4 \pm 2.63^{b-d}$ & $24.0 \pm 3.23$ ede & $16.9 \pm 1.71^{\mathrm{cd}}$ & $16.0 \pm 2.06^{b}$ \\
\hline Siyah Kişmiş & $167.2 \pm 34.79^{\circ}$ & $179.7 \pm 57.98 \mathrm{q}$ & $27.8 \pm 2.94^{\mathrm{a}-\mathrm{c}}$ & $25.6 \pm 3.22$ b-e & $18.6 \pm 2.34^{\mathrm{a}-\mathrm{c}}$ & $19.5 \pm 2.22^{\mathrm{a}}$ \\
\hline Boğa Üzümü & $211.9 \pm 24.07^{f}$ & $193.7 \pm 43.51^{\mathrm{m}}$ & $22.8 \pm 3.23^{d}$ & $23.4 \pm 3.59$ de & $15.4 \pm 2.28^{\mathrm{d}}$ & $17.5 \pm 3.32$ ab \\
\hline Kırmızı Üzüm & $232.5 \pm 37.69^{\mathrm{d}}$ & $223.1 \pm 19.76^{g}$ & $25.6 \pm 3.28$ cd & $25.5 \pm 2.60^{\text {b-e }}$ & $16.6 \pm 2.12^{\mathrm{cd}}$ & $18.7 \pm 2.20 \mathrm{ab}$ \\
\hline Miri & $191.6 \pm 31.07 \mathrm{kl}$ & $220.0 \pm 28.17^{h}$ & $26.5 \pm 2.95^{b-d}$ & $27.1 \pm 2.93^{\mathrm{ab}}$ & $15.4 \pm 2.04^{\mathrm{d}}$ & $17.7 \pm 2.74$ ab \\
\hline Kırmızı Miri & $206.3 \pm 51.50^{\mathrm{gh}}$ & $225.3 \pm 51.46^{g}$ & $26.0 \pm 3.88^{\mathrm{cd}}$ & $25.6 \pm 3.57$ b-e & $17.8 \pm 3.40^{a-d}$ & $17.4 \pm 2.96^{\mathrm{ab}}$ \\
\hline Kuş Üzümü & $191.4 \pm 50.67 \mathrm{kl}$ & $186.8 \pm 26.40$ no & $29.2 \pm 3.22^{a b}$ & $29.3 \pm 4.26^{\mathrm{a}}$ & $17.6 \pm 3.05^{\mathrm{a}-\mathrm{d}}$ & $18.9 \pm 1.92^{\text {а }}$ \\
\hline Kuş Üzümü-2 & $158.2 \pm 41.05^{\mathrm{p}}$ & $178.8 \pm 35.72$ q & $29.2 \pm 2.76 \mathrm{ab}$ & $25.9 \pm 4.69$ b-е & $18.1 \pm 2.11^{\mathrm{a}-\mathrm{d}}$ & $17.7 \pm 2.33$ ab \\
\hline Reşa Aliya & $231.6 \pm 46.07^{\mathrm{d}}$ & $204.3 \pm 30.63^{\mathrm{kl}}$ & $25.2 \pm 3.39^{\mathrm{d}}$ & $25.9 \pm 2.41^{\text {b-e }}$ & $18.5 \pm 2.61^{\mathrm{a}-\mathrm{c}}$ & $18.4 \pm 2.05^{\mathrm{ab}}$ \\
\hline Kırmızı Güzane & $213.8 \pm 20.58^{f}$ & $217.5 \pm 43.01^{\mathrm{i}}$ & $26.7 \pm 4.03^{b-d}$ & $26.7 \pm 4.03^{\mathrm{a}-\mathrm{c}}$ & $19.1 \pm 3.36^{a b}$ & $19.1 \pm 3.37^{\mathrm{a}}$ \\
\hline Siyah Güzane & $189.1 \pm 53.45^{1}$ & $206.3 \pm 64.30^{\mathrm{k}}$ & $27.0 \pm 3.32^{b-d}$ & $25.7 \pm 4.06$ b-e & $17.9 \pm 2.11^{\mathrm{a}-\mathrm{d}}$ & $18.0 \pm 3.11^{\mathrm{ab}}$ \\
\hline Beyaz Binetati & $247.1 \pm 32.26^{\mathrm{c}}$ & $289.6 \pm 56.03^{a}$ & $25.2 \pm 5.90^{d}$ & $26.0 \pm 3.59^{a-d}$ & $17.7 \pm 3.52^{a-d}$ & $18.6 \pm 2.19^{a b}$ \\
\hline Binetati-2 & $207.7 \pm 35.95^{g}$ & $248.3 \pm 42.74^{d}$ & $26.8 \pm 3.27$ b-d & $27.6 \pm 2.97 \mathrm{ab}$ & $16.6 \pm 2.37$ cd & $19.0 \pm 2.86^{\mathrm{a}}$ \\
\hline Pekmezlik & $270.8 \pm 64.52^{b}$ & $267.5 \pm 54.60^{b}$ & $25.7 \pm 4.03^{\mathrm{cd}}$ & $25.9 \pm 3.24^{\text {b-e }}$ & $15.5 \pm 1.84^{\mathrm{d}}$ & $16.9 \pm 2.25^{b}$ \\
\hline Ortalama & 205.4 & 210.0 & 26,4 & 25.8 & 17.3 & 17.9 \\
\hline Maksimum & 281,0 & 289,6 & 30,6 & 29.9 & 20.0 & 19.5 \\
\hline Minimum & 146,3 & 153,1 & 22.8 & 22.1 & 15.1 & 16.0 \\
\hline
\end{tabular}

*: Aynı sütunda farklı harflerle gösterilen ortalamalar arasındaki fark önemlidir (LSD: \%5). 
Çizelge 4. Alınma konumuna göre yapraklarda saptanan stoma yoğunlukları ve boyutları

\begin{tabular}{|c|c|c|c|c|c|c|}
\hline \multirow[t]{2}{*}{ Çeşitler } & \multicolumn{2}{|c|}{ Stoma yoğunluğu (adet $\left./ \mathrm{mm}^{2}\right)$} & \multicolumn{2}{|c|}{ Stoma boyu $(\mu \mathrm{m})$} & \multicolumn{2}{|c|}{ Stoma eni $(\mu \mathrm{m})$} \\
\hline & Gölge & Güneş & Gölge & Güneş & Gölge ** & Güneş ** \\
\hline Tortor & $189.2 \pm 29.99^{\text {ef* }^{*}}$ & $315.9 \pm 20.02^{a}$ & $28.0 \pm 3.59^{\mathrm{a}-\mathrm{d}}$ & $25.3 \pm 3.50^{\mathrm{a}-\mathrm{d}}$ & $17.59 \pm 3.41$ & $17.50 \pm 3.76$ \\
\hline Hüsni Beyaz & $155.7 \pm 7.49^{\mathrm{jk}}$ & $214.3 \pm 7.59^{k}$ & $25.3 \pm 3.65^{\mathrm{cd}}$ & $26.3 \pm 3.59^{\mathrm{a}-\mathrm{c}}$ & $17.47 \pm 2.46$ & $17.10 \pm 2.44$ \\
\hline Siyah Sinciri & $175.8 \pm 25.55^{\mathrm{gh}}$ & $250.9 \pm 31.07$ de & $23.6 \pm 3.20^{d}$ & $27.7 \pm 3.09 \mathrm{ab}$ & $17.11 \pm 3.31$ & $17.71 \pm 2.71$ \\
\hline Beyaz Sinciri & $120.7 \pm 7.72$ р & $198.6 \pm 23.84^{\mathrm{m}}$ & $24.2 \pm 3.43^{d}$ & $26.0 \pm 3.80^{a-c}$ & $17.12 \pm 2.80$ & $17.45 \pm 3.42$ \\
\hline Tilka Piri & $162.0 \pm 14.63^{\mathrm{j}}$ & $218.0 \pm 7.36^{\mathrm{jk}}$ & $24.4 \pm 2.95^{\mathrm{d}}$ & $23.1 \pm 3.39 \mathrm{~cd}$ & $17.38 \pm 3.07$ & $16.67 \pm 3.01$ \\
\hline Ziraat Üzümü & $188.2 \pm 15.47^{\mathrm{f}}$ & $255.9 \pm 28.27^{\mathrm{d}}$ & $27.7 \pm 4.11^{b-d}$ & $27.1 \pm 4.89$ ab & $20.05 \pm 2.38$ & $18.98 \pm 2.91$ \\
\hline Beyaz Güzane & $179.7 \pm 22.06^{g}$ & $243.4 \pm 30.17^{\mathrm{f}}$ & $24.9 \pm 4.64^{\mathrm{d}}$ & $26.1 \pm 3.65^{\mathrm{a}-\mathrm{c}}$ & $16.90 \pm 3.53$ & $18.38 \pm 3.17$ \\
\hline Kırmızı Tayifi & $177.1 \pm 21.25^{g}$ & $255.6 \pm 22.59^{d}$ & $24.3 \pm 3.22^{\mathrm{d}}$ & $28.6 \pm 3.87^{\mathrm{a}}$ & $16.70 \pm 2.76$ & $18.80 \pm 1.68$ \\
\hline Tayifi-2 & $185.8 \pm 8.19^{\mathrm{f}}$ & $250.8 \pm 7.06^{\mathrm{e}}$ & $23.1 \pm 3.71^{d}$ & $21.8 \pm 3.28^{d}$ & $15.93 \pm 2.25$ & $15.32 \pm 2.24$ \\
\hline Tayifi-3 & $139.4 \pm 17.97 \mathrm{~m}$ & $221.2 \pm 8.66^{\mathrm{ij}}$ & $25.4 \pm 4.00^{\mathrm{cd}}$ & $26.5 \pm 4.61 \mathrm{ab}$ & $17.08 \pm 3.16$ & $18.30 \pm 2.87$ \\
\hline Yediveren & $161.8 \pm 14.62^{j}$ & $236.4 \pm 7.55^{g}$ & $26.8 \pm 3.84^{\mathrm{cd}}$ & $26.1 \pm 3.73^{\text {a-c }}$ & $16.04 \pm 3.05$ & $16.49 \pm 3.34$ \\
\hline Alaki & $218.8 \pm 14,84^{b}$ & $316.3 \pm 20.62^{a}$ & $23.7 \pm 3.53^{d}$ & $25.8 \pm 2.74^{\mathrm{a}-\mathrm{c}}$ & $16.76 \pm 3.82$ & $17.16 \pm 2.95$ \\
\hline Siyah Üzüm & $140.0 \pm 13.77^{\mathrm{m}}$ & $199.1 \pm 20.83^{\mathrm{m}}$ & $30.1 \pm 4.42 \mathrm{ab}$ & $28.7 \pm 4.32^{\mathrm{a}}$ & $18.10 \pm 2.87$ & $17.32 \pm 3.38$ \\
\hline Bagıltı Bisti Sipi & $113.9 \pm 9.65$ q & $186.1 \pm 4.79^{n}$ & $30.3 \pm 5.19^{\text {a }}$ & $29.8 \pm 4.42^{\mathrm{a}}$ & $19.92 \pm 3.52$ & $19.44 \pm 3.69$ \\
\hline Bagıltı Bisti Hışin & $160.4 \pm 14.89^{j}$ & $252.6 \pm 9.26$ de & $25.7 \pm 3.27 \mathrm{~cd}$ & $24.8 \pm 3.04^{b-d}$ & $16.52 \pm 1.88$ & $16.35 \pm 2.03$ \\
\hline Siyah Kişmiş & $131.3 \pm 5.76^{\circ}$ & $215.6 \pm 19.10^{\mathrm{k}}$ & $27.3 \pm 2.80^{\mathrm{cd}}$ & $26.1 \pm 3.60^{\mathrm{a}-\mathrm{c}}$ & $18.95 \pm 1.88$ & $19.18 \pm 2.70$ \\
\hline Boğa Üzümü & $173.4 \pm 22.80^{\mathrm{h}}$ & $232.1 \pm 9.09^{\mathrm{h}}$ & $22.9 \pm 2.94^{\mathrm{d}}$ & $23.4 \pm 3.85^{\mathrm{cd}}$ & $16.59 \pm 2.73$ & $16.21 \pm 3.32$ \\
\hline Kırmızı Üzüm & $203.1 \pm 7.92^{d}$ & $252.5 \pm 18.29$ de & $25.8 \pm 3.03^{\mathrm{cd}}$ & $25.3 \pm 2.87^{b-d}$ & $17.60 \pm 1.91$ & $17.70 \pm 2.84$ \\
\hline Miri & $179.5 \pm 18.28 \mathrm{~g}$ & $232.1 \pm 15.64^{\mathrm{h}}$ & $27.0 \pm 2.53^{\mathrm{cd}}$ & $26.6 \pm 3.31 \mathrm{ab}$ & $16.05 \pm 2.03$ & $17.04 \pm 3.10$ \\
\hline Kırmızı Miri & $169.1 \pm 11.10^{\mathrm{i}}$ & $262.5 \pm 12.46^{c}$ & $25.4 \pm 3.84^{\mathrm{cd}}$ & $26.2 \pm 3.58^{\mathrm{a}-\mathrm{c}}$ & $17.86 \pm 3.16$ & $17.31 \pm 3.21$ \\
\hline Kuş Üzümü & $154.3 \pm 11.41^{\mathrm{k}}$ & $223.8 \pm 15.67^{\mathrm{i}}$ & $29.8 \pm 3.522^{a b}$ & $28.8 \pm 3.95^{\mathrm{a}}$ & $18.59 \pm 2.50$ & $17.90 \pm 2.69$ \\
\hline Kuş Üzümü-2 & $134.0 \pm 15.59^{n}$ & $203.0 \pm 10.98^{1}$ & $28.8 \pm 4.61^{\mathrm{a}-\mathrm{c}}$ & $26.4 \pm 3.44^{\mathrm{ab}}$ & $17.93 \pm 2.53$ & $17.85 \pm 1.88$ \\
\hline Reşa Aliya & $183.8 \pm 12.19^{f}$ & $252.1 \pm 23.61$ de & $25.6 \pm 3.17$ cd & $25.5 \pm 2.75^{\mathrm{a}-\mathrm{c}}$ & $18.76 \pm 2.76$ & $18.12 \pm 1.80$ \\
\hline Kırmızı Güzane & $187.6 \pm 11.86^{f}$ & $243.8 \pm 15.73^{f}$ & $26.0 \pm 4.20^{\mathrm{cd}}$ & $27.3 \pm 3.72^{a b}$ & $18.78 \pm 3.98$ & $19.36 \pm 2.57$ \\
\hline Siyah Güzane & $144.2 \pm 8.53^{1}$ & $251.2 \pm 15.37$ de & $26.4 \pm 4.32^{\mathrm{cd}}$ & $26.3 \pm 3.11^{\mathrm{a}-\mathrm{c}}$ & $17.98 \pm 3.02$ & $17.90 \pm 2.24$ \\
\hline Beyaz Binetati & $228.7 \pm 13.67^{\text {a }}$ & $308.0 \pm 36.07^{b}$ & $24.5 \pm 3.74^{\mathrm{d}}$ & $26.6 \pm 5.644^{a b}$ & $17.51 \pm 2.40$ & $18.88 \pm 3.29$ \\
\hline Binetati-2 & $192.4 \pm 19.79$ е & $263.6 \pm 26.08^{c}$ & $27.3 \pm 3.05^{\mathrm{cd}}$ & $27.2 \pm 3.24^{\mathrm{ab}}$ & $17.41 \pm 2.80$ & $18.11 \pm 2.95$ \\
\hline Pekmezlik & $215.4 \pm 7.78^{\mathrm{c}}$ & $322.9 \pm 12.51^{\mathrm{a}}$ & $24.3 \pm 4.38^{\mathrm{d}}$ & $24.0 \pm 3.50^{\mathrm{cd}}$ & $16.15 \pm 2.09$ & $16.23 \pm 3.76$ \\
\hline Ortalama & 170.2 & 245.7 & 26.0 & 26.2 & 17,53 & 17,67 \\
\hline Maksimum & 228.7 & 322,9 & 30.3 & 29.8 & 20,05 & 19,44 \\
\hline Minimum & 113.9 & 186,1 & 22.9 & 21.8 & 15,93 & 15,32 \\
\hline
\end{tabular}

*: Aynı sütunda farklı harflerle gösterilen ortalamalar arasındaki fark önemlidir (LSD: \%5); **: Fark önemli değildir. 


\section{2. Üzüm çeşitlerinin klorofil ve karotenoid miktarları ile SPAD değerlerine ait bulgular}

Çalışmada klorofil a, klorofil b, toplam klorofil ve karotenoid miktarları üzerine çeşidin, SPAD değerleri üzerine ise çeşit ve yaprağın alınma konumunun (gölge/güneş) etkisi istatistiki olarak $(\mathrm{p}<0.001)$ oldukça önemli bulunmuştur (Çizelge 5).

Çizelge 5. Klorofil ve karotenoid miktarları ile SPAD değerlerine ilişkin varyans analiz sonuçları

\begin{tabular}{|c|c|c|c|c|c|}
\hline & Varyasyon Kaynağ1 & S.D. & K.T. & K.O. & F-Değeri \\
\hline & A: Çeşit & 27 & 7.56385 & 0.280142 & $5.95 * * *$ \\
\hline \multirow[t]{2}{*}{ Klorofi a } & Hata & 56 & 2.6358 & 0.0470678 & \\
\hline & Toplam & 83 & 10.1996 & & \\
\hline & A: Çeşit & 27 & 0.648035 & 0.0240013 & $5.26 * * *$ \\
\hline \multirow[t]{2}{*}{ Klorofi b } & Hata & 56 & 0.255443 & 0.00456149 & \\
\hline & Toplam & 83 & 0.903478 & & \\
\hline \multirow{3}{*}{ Toplam klorofil } & A: Çeşit & 27 & 12.335 & 0.456852 & $5.77 * * *$ \\
\hline & Hata & 56 & 4.43497 & 0.079196 & \\
\hline & Toplam & 83 & 16.77 & & \\
\hline \multirow{3}{*}{ Karotenoid } & A: Çeşit & 27 & 5.64355 & 0.20902 & $7.04 * * *$ \\
\hline & Hata & 56 & 1.66232 & 0.0296843 & \\
\hline & Toplam & 83 & 7.30587 & & \\
\hline \multirow[t]{4}{*}{ SPAD değerleri } & A: Çeşit & 27 & 34.94 & 11.02 & $2.52 * * *$ \\
\hline & B: Gölge / Güneş & 1 & 303.041 & 95.60 & $15.90 * * *$ \\
\hline & Hata & 27 & 85.5879 & 3.16992 & \\
\hline & Toplam & 55 & 1332.07 & & \\
\hline
\end{tabular}

$* * *:(\mathrm{p}<0.001)$.

Çalışmada klorofil a, klorofil b, toplam klorofil ve karotenoid miktarları ile SPAD değerleri açısından çeşitler arasında istatistiki olarak farklılık olduğu tespit edilmiştir. Üzüm çeşitlerinin ortalama klorofil a, klorofil b, toplam klorofil ve karotenoid miktarları sirasiyla $1.33-0.38-1.71$ ve $1.52 \mathrm{mg} / \mathrm{g}$ olarak bulunmuştur. En düşük klorofil a, klorofil b, toplam klorofil ve karotenoid miktarları Kırmızı Tayifi çeşidinde (sırasıyla $0.75,0.24,0.99$ ve 1.08 ), en yüksek klorofil a ve toplam klorofil miktarları Reşe Aliya çeşidinde (sırasıyla 2.07 ve $2.66 \mathrm{mg} / \mathrm{g}$ ), en yüksek klorofil b ve karotenoid miktarları ise Beyaz Bineteti çeşidinde (sırasıyla 0.59 ve $2.00 \mathrm{mg} / \mathrm{g}$ ) ölçülmüştür. Gölgede ve güneşte bulunan yapraklarda ölçülen en düşük SPAD değerleri Bineteti 2 çeşidinden [22.32 (gölge) ve 27.48 (güneş)] elde edilirken, en yüksek SPAD değerleri ise Reşe Alya çeşidinden [40.62 (gölge) ve 45.78 (güneş)] elde edilmiştir. Tüm çeşitlerde güneşte bulunan yaprakların SPAD değerleri gölgede bulunan yapraklara göre daha yüksek bulunmuştur (Çizelge 6). Değişik meyve türlerinde yapılan çalışmalarda da klorofil miktarlarının türlere ve çeşitlere göre önemli farkl1lıklar gösterdiği bildirilmiştir (Gargın ve Göktaş, 2011; Muradoğlu ve Gündoğdu, 2011; Alkan ve ark., 2014). Uyak ve ark. (2016), inceledikleri üzüm çeşitlerinde ortalama toplam klorofil, klorofil a ve klorofil b miktarlarını sirasıyla 1.90-1.18 ve 0.71 $\mathrm{mg} / \mathrm{g}$ olarak rapor etmiş ve çeşitler arasında bu özellikler bakımından istatistiksel olarak önemli farklılıkların olduğunu bildirmişlerdir. Araştırıcılar en düşük toplam klorofil, klorofil a ve klorofil b miktarlarını Yalova İncisinde (sırasıyla $0.87-0.53$ ve $0.34 \mathrm{mg} / \mathrm{g}$ ) , en yüksek toplam klorofil, klorofil a ve klorofil b miktarlarını ise Erciş üzüm çeşidinde (2.52-1.56 ve $0.96 \mathrm{mg} / \mathrm{g}$ ) tespit etmişlerdir. Gargın (2011), incelemiş olduğu 13 Amerikan asma anacının SPAD değerleri arasında önemli farklı1ıkların olduğunu ve SPAD değerlerinin 20.62-30.19 değerleri arasında değiştiğini bildirmiştir. Erez ve ark. (2017), Siirt yöresinde yetiştirilen üzüm çeşitlerinde en yüksek toplam klorofil miktarlarını Gadüv (16.64 mg/g), Karrot (13.60 mg/g) ve Heseni $(13.45 \mathrm{mg} / \mathrm{g})$ çeşitlerinde, en düşük toplam klorofil miktarlarını ise Besirane (5.64 mg/g), Rutik (4.72 mg/g) ve Spiyo (4.95 mg/g) çeşitlerinde belirlemişlerdir. Araştırıcılar, en yüksek toplam karotenoid miktarını Gadüv çeşidinde $(0.19 \mathrm{mg} / \mathrm{g})$, en düşük karotenoid miktarını ise Kıtılnefs $(0.06 \mathrm{mg} / \mathrm{g})$ çeşidinde tespit etmişlerdir. Porro ve ark. (2002), Chardonnay üzüm çeşidinde fenolojik evrelere ve yaprakların sürgün üzerindeki pozisyonlarına göre SPAD değerlerinin değişimini incelemişlerdir. Araştırıcılar, 35-40 günlük yapraklarda 35 SPAD değerini saptarken; 90-100 günlük yapraklarda >40 SPAD değerini belirlemişlerdir. Yapraklarda bulunan klorofil miktarının hayat formu, mevsim ve 1şık koşulları gibi faktörlerin etkisi ile geniş bir değişkenlik gösterdiği ifade edilmiştir (Kutbay ve Kılınç, 1992). 


\section{Sonuç}

Çalışmada çeşit, yöntem ve yaprağın alındığı konumun stoma yoğunluğu üzerine olan etkisinin önemli olduğu ancak yaprak yüzeyinin farklı yerlerinden örnek almanın stoma yoğunluğu üzerine etkisinin önemsiz olduğu tespit edilmiştir. Aynı şekilde, çeşit ve yöntemin stoma boyutları üzerine olan etkilerinin önemli olduğu ancak yaprağın alınma yerinin ve yaprak yüzeyinin farklı yerlerinden örnek almanın stoma boyutları üzerine olan etkisinin önemsiz olduğu belirlenmiştir. Uygulanan yöntem ve yaprakların alınma konumlarına göre stoma yoğunluğu ve boyutları açısından çeşitler arasında farklılık olduğu tespit edilmiştir. Stoma yoğunluğu bakımından çeşitler arasındaki farklılığın önemli bulunması, belirli bir koşulda stoma yoğunluğunun çeşide özgü olduğunu açıkça ortaya koymaktadır. Genel olarak stoma boyutları küçüldükçe stoma yoğunluğunun artma eğilimi gösterdiği gözlemlenmiştir. Kalıp alma metodunda 16 çeşitte saydamlaştırma metoduna göre stoma yoğunlukları daha yüksek bulunurken, saydamlaştırma metodunda ise 12 çeşitte stoma yoğunluğunun daha yüksek olduğu belirlenmiştir. Saydamlaştırma metodunun daha net bir bakı alanı sağlamış olması bazı çeşitlerde stoma yoğunluğunun daha yüksek çıkmasının nedeni olarak düşünülmektedir. Tüm çeşitlerde her iki yöntemde de güneşte olan yapraklardaki stoma yoğunlukları gölgede olan yapraklara göre daha yüksek bulunmuştur.

Stomaların bir kısmı yaprak mezofil dokusunun mantar tabakası içinde gömülmüş olarak bulunduğu için bu stomaların kalıpta iz bırakması için tırnak cilasının firçayla yanal sürülmesinden sonra hızlıca yaprak yüzeyine dik firça darbeleri ile iyice yaprak yüzeyine oturmasını sağlamak önemli tespit ettiğimiz husus olmuştur. Bir başka husus ise tırnak cilasının tamamen kurumasından sonra tırnak cilası üzerine yapıştırılan şeffaf bantın yapışma yüzeyinin kaliteli (yapışkanlık değerinin yüksek olması) olması ve bant yüzeyinde imalat esnasında hava kabarcıklarının kalmamasıdır.

Tırnak cilası ile şeffaf bant arasında tam yapışma olmadığı durumlarda hava kabarcıklarının bulunduğu yerlere denk gelen stomaların kalıba taşınmadığı gözlemlenmiştir. Kalıp almada muhtelif şeffaf bant markaları kullanılmış en olumlu sonucun "Vega" marka şeffaf bantla sağlandığı tespit edilmiştir. Kalıp almada en iyi sonuç Flormar-FC36 tırnak cilasından elde edilmiştir. Tüylü ve yüzeyi pürüzlü asma yapraklarında daha iyi bir stomal gözlemlemenin yapılmasında saydamlaştırma yönteminin tercih edilmesi gerektiği kanaatine varılmıştır. Elde edilen bulgulara dayanarak, saydamlaştırma yönteminde yaprakların tam olarak saydamlaşmasının 24-36 saat aldığı, kullanılacak olan piyasada satılan hipoların muhtelif konsantrasyonlarda bulunduğu unutulmamalıdır. Kaliteli hipo markaların tercih edilmesi ile daha net saydamlaşmış yüzey elde edilebildiği saptanmıştır.

Çalışmada çeşidin toplam klorofil, klorofil a, klorofil $b$ ve karotenoid miktarları ile SPAD değerleri üzerine olan etkisinin önemli olduğu tespit edilmiştir. Çeşitler arasında bu değerler bakımından önemli farklılıklar olduğu belirlenmiştir. Güneşte olan yaprakların SPAD değerlerinin gölgede olan yapraklara göre daha yüksek olduğu gözlemlenmiştir. 
Çizelge 6. Yapraklarda saptanan klorofil ve karotenoid miktarları ile SPAD değerleri

\begin{tabular}{|c|c|c|c|c|c|c|}
\hline Çeşit & Klorofil a (mg/g) & Klorofil b (mg/g) & Toplam klorofil (mg/g) & Karotenoid (mg/g) & SPAD/ Gölge & SPAD/ Güneş \\
\hline Tortor & $1.06 \pm 0.156^{\mathrm{h}-\mathrm{k}^{*}}$ & $0.31 \pm 0.033^{\mathrm{e}-\mathrm{i}}$ & $1.37 \pm 0.186^{\mathrm{f}-\mathrm{h}}$ & $1.26+0.036^{\mathrm{i}-\mathrm{l}}$ & $30.27^{\text {b-e }}$ & $35.43^{\text {b-e }}$ \\
\hline Hüsni Beyaz & $1.62 \pm 0.325^{b-d}$ & $0.44 \pm 0.099 \mathrm{bc}$ & $2.06 \pm 0.423$ bc & $1.77+0.151^{\mathrm{a}-\mathrm{d}}$ & $31.42^{b-d}$ & $36.58^{b-d}$ \\
\hline Siyah Sinciri & $1.58 \pm 0.151^{\mathrm{b}-\mathrm{d}}$ & $0.39 \pm 0.029$ b-f & $1.97 \pm 0.180^{c}$ & $1.84+0.122^{\mathrm{a}-\mathrm{d}}$ & 34.37 bc & 39.53 bc \\
\hline Beyaz Sinciri & $1.19 \pm 0.111^{e-j}$ & $0.31 \pm 0.025^{\mathrm{d}-\mathrm{i}}$ & $1.50 \pm 0.135^{\mathrm{d}-\mathrm{g}}$ & $1.45+0.084^{\mathrm{e}-\mathrm{i}}$ & $25.02^{\mathrm{e}}$ & $30.18^{e}$ \\
\hline Tilka Piri & $1.86 \pm 0.252^{\mathrm{a}-\mathrm{c}}$ & $0.58 \pm 0.103^{a}$ & $2.44 \pm 0.354$ ab & $1.76+0.129^{a-d}$ & $29.82^{\text {c-e }}$ & $34.98^{\text {c-e }}$ \\
\hline Ziraat Üzümü & $1.04 \pm 0.234^{h-k}$ & $0.33 \pm 0.079^{c-i}$ & $1.38 \pm 0.313^{\mathrm{f}-\mathrm{h}}$ & $1.11+0.181 \mathrm{kl}$ & 26.97 de & 32.13 de \\
\hline Beyaz Güzane & $1.33 \pm 0.108^{\mathrm{d}-\mathrm{i}}$ & $0.42 \pm 0.020^{b-d}$ & $1.76 \pm 0.104^{c-f}$ & $1.67+0.048^{b-e}$ & 32.32 bc & 37.48 bc \\
\hline Kırmızı Tayifi & $0.75 \pm 0.046^{\mathrm{k}}$ & $0.24 \pm 0.005^{\mathrm{i}}$ & $0.99 \pm 0.050^{h}$ & $1.08+0.120^{l}$ & $25.42^{\text {e }}$ & $30.58^{\mathrm{e}}$ \\
\hline Tayifi-2 & $1.30 \pm 0.156^{\mathrm{d}-\mathrm{i}}$ & $0.34 \pm 0.037^{c-i}$ & $1.64 \pm 0.194^{\mathrm{c}-\mathrm{f}}$ & $1.35+0.143^{\mathrm{g}-\mathrm{l}}$ & $33.42^{b c}$ & $38.58^{\text {bc }}$ \\
\hline Tayifi-3 & $0.99 \pm 0.086^{i-k}$ & $0.32 \pm 0.014^{\mathrm{d}-\mathrm{i}}$ & $1.32 \pm 0.100^{\mathrm{f}-\mathrm{h}}$ & $1.41+0.124^{e-j}$ & $29.17^{\text {c-e }}$ & 34.33 de \\
\hline Yediveren & $1.36 \pm 0.030^{\mathrm{d}-\mathrm{h}}$ & $0.40 \pm 0.012^{\text {b-e }}$ & $1.76 \pm 0.042^{\mathrm{c}-\mathrm{f}}$ & $1.25+0.161^{\mathrm{i}-1}$ & 33.12 bc & 38.28 bc \\
\hline Alaki & $1.54 \pm 0.069^{b-d}$ & $0.40 \pm 0.025$ b-e & $1.94 \pm 0.092^{\mathrm{cd}}$ & $1.93+0.069 a$ & 33.77 bc & 38.93 bc \\
\hline Siyah Üzüm & $1.32 \pm 0.083^{\mathrm{d}-\mathrm{i}}$ & $0.39 \pm 0.046^{b-f}$ & $1.71 \pm 0.129^{\mathrm{c}-\mathrm{f}}$ & $1.75+0.067^{\mathrm{a}-\mathrm{d}}$ & $30.07^{\text {c-e }}$ & $35.23^{\text {c-e }}$ \\
\hline Bagıltı Bisti Sipi & $1.30 \pm 0.602^{\mathrm{d}-\mathrm{i}}$ & $0.39 \pm 0.164^{b-f}$ & $1.69 \pm 0.766^{c-f}$ & $1.56+0.543^{d-h}$ & $30.90^{b-d}$ & $36.07^{b-d}$ \\
\hline Bagıltı Bisti Hışin & $1.05 \pm 0.246^{h-k}$ & $0.29 \pm 0.054^{\mathrm{f}-\mathrm{i}}$ & $1.34 \pm 0.298^{\mathrm{f}-\mathrm{h}}$ & $1.13+0.079^{\mathrm{j}-1}$ & 32.82 bc & 37.98 bc \\
\hline Siyah Kişmiş & $1.29 \pm 0.159^{\mathrm{d}-\mathrm{i}}$ & $0.40 \pm 0.066$ b-e & $1.69 \pm 0.223^{\mathrm{c}-\mathrm{f}}$ & $1.37+0.165^{\mathrm{f}-\mathrm{k}}$ & 28.12 de & 33.28 de \\
\hline Boğa Üzümü & $1.45 \pm 0.091^{\mathrm{d}-\mathrm{f}}$ & $0.40 \pm 0.045^{\text {b-e }}$ & $1.85 \pm 0.135^{\text {c-e }}$ & $1.57+0.161^{\mathrm{d}-\mathrm{h}}$ & $30.87^{b-d}$ & $36.03^{b-d}$ \\
\hline Kırmızı Üzüm & $1.15 \pm 0.074^{f-j}$ & $0.32 \pm 0.020^{\mathrm{d}-\mathrm{i}}$ & $1.48 \pm 0.093^{\mathrm{e}-\mathrm{g}}$ & $1.37+0.039^{\mathrm{f}-\mathrm{k}}$ & $36.07^{b}$ & $41.23^{b}$ \\
\hline Miri & $1.42 \pm 0.161^{\mathrm{d}-\mathrm{g}}$ & $0.42 \pm 0.066^{b-d}$ & $1.84 \pm 0.227^{\text {c-e }}$ & $1.58+0.176^{\mathrm{d}-\mathrm{g}}$ & 31.57 bc & 36.73 bc \\
\hline Kırmızı Miri & $1.35 \pm 0.259^{\mathrm{d}-\mathrm{h}}$ & $0.38 \pm 0.076^{b-g}$ & $1.72 \pm 0.329^{c-f}$ & $1.87+0.169^{\mathrm{a}-\mathrm{c}}$ & $36.17^{\mathrm{b}}$ & $41.33^{b}$ \\
\hline Kuş Üzümü & $1.47 \pm 0.205^{\mathrm{d}-\mathrm{f}}$ & $0.38 \pm 0.078^{b-f}$ & $1.85 \pm 0.280^{\text {c-e }}$ & $1.62+0.175^{\mathrm{c}-\mathrm{f}}$ & $26.72^{\mathrm{e}}$ & $31.88^{\mathrm{e}}$ \\
\hline Kuş Üzümü-2 & $1.05 \pm 0.384^{\mathrm{h}-\mathrm{k}}$ & $0.35 \pm 0.125^{\text {b-h }}$ & $1.40 \pm 0.509^{\text {e-h }}$ & $1.30+0.357^{\text {h-l }}$ & 28.57 de & 33.73 de \\
\hline Reşa Aliya & $2.07 \pm 0.224^{\mathrm{a}}$ & $0.58 \pm 0.041^{\mathrm{a}}$ & $2.66 \pm 0.261^{\mathrm{a}}$ & $1.80+0.118^{\mathrm{a}-\mathrm{d}}$ & $40.62^{\mathrm{a}}$ & $45.78^{a}$ \\
\hline Kırmızı Güzane & $1.35 \pm 0.197^{\mathrm{d}-\mathrm{h}}$ & $0.33 \pm 0.044^{\mathrm{c}-\mathrm{i}}$ & $1.68 \pm 0.241^{\mathrm{c}-\mathrm{f}}$ & $1.65+0.091$ b-e & $30.32^{b-d}$ & $35.48^{b-d}$ \\
\hline Siyah Güzane & $1.53 \pm 0.262^{\text {c-e }}$ & $0.45 \pm 0.088^{b}$ & $1.98 \pm 0.348^{c}$ & $1.59+0.104^{c-f}$ & $40.02^{\mathrm{a}}$ & $45.18^{\mathrm{a}}$ \\
\hline Beyaz Binetati & $1.89 \pm 0.049 a b$ & $0.59 \pm 0.042^{\mathrm{a}}$ & $2.48 \pm 0.092^{a b}$ & $2.00+0.153^{a}$ & $31.17^{b-d}$ & $36.33^{b-d}$ \\
\hline Binetati-2 & $0.84 \pm 0.083^{j k}$ & $0.27 \pm 0.014$ & $1.11 \pm 0.095$ gh & $1.21+0.053^{i-1}$ & $22.32^{f}$ & $27.48^{f}$ \\
\hline Pekmezlik & $1.10 \pm 0.251^{\mathrm{g}-\mathrm{k}}$ & $0.27 \pm 0.110^{g-i}$ & $1.37 \pm 0.359^{\mathrm{f}-\mathrm{h}}$ & $1.26+0.125^{\mathrm{i}-\mathrm{l}}$ & $27.42^{\text {de }}$ & 32.58 de \\
\hline Ortalama & 1.33 & 0.38 & 1.71 & 1.52 & 31.03 & 36.19 \\
\hline Maksimum & 2.07 & 0.59 & 2.66 & 2.00 & 40,62 & 45,78 \\
\hline Minimum & 0.75 & 0.24 & 0.99 & 1.08 & 22,32 & 27,48 \\
\hline
\end{tabular}

*: Aynı sütunda farklı harflerle gösterilen ortalamalar arasındaki fark önemlidir (LSD : \%5). 

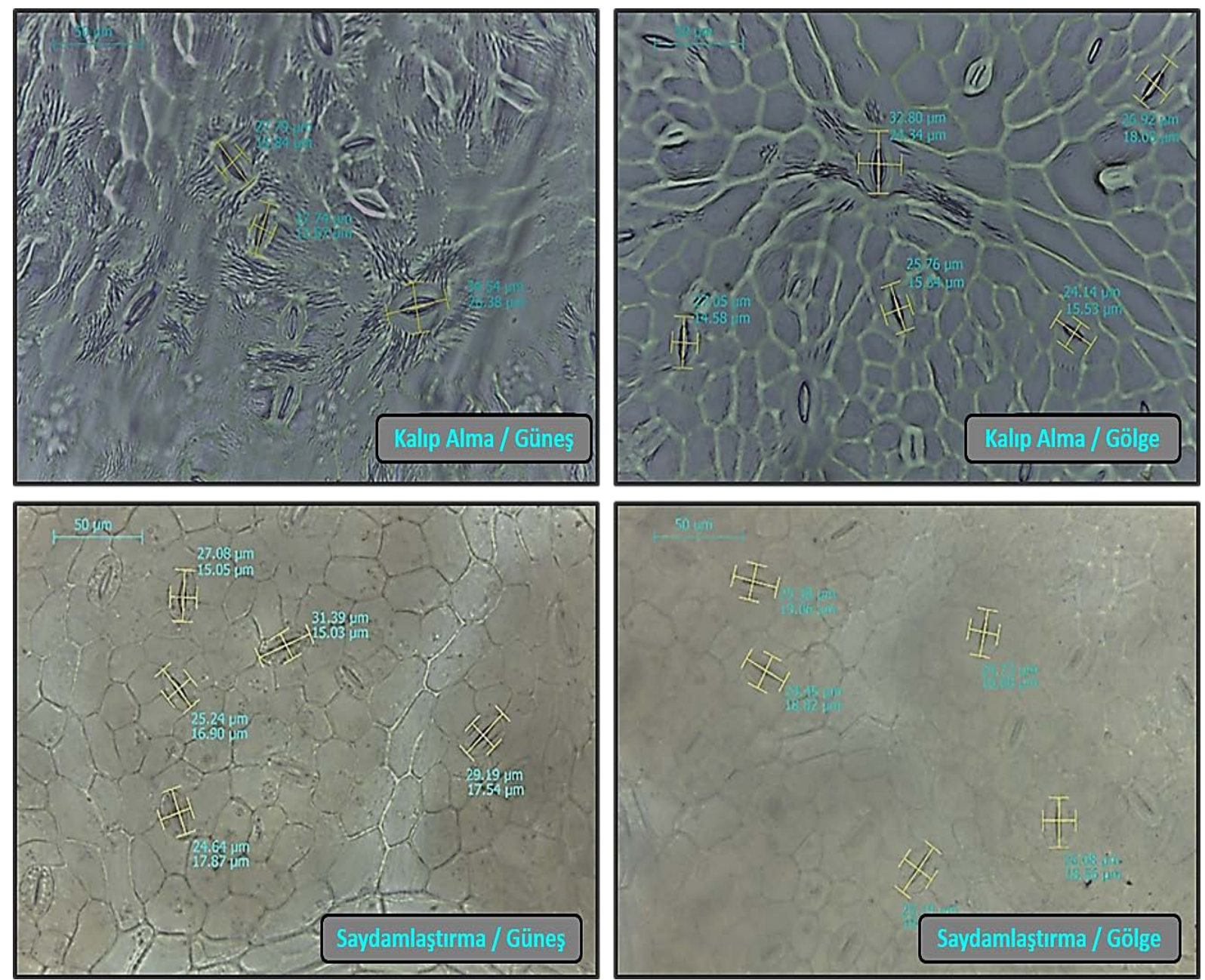

Şekil 1. Tayfi -2 üzüm çeşidinde stoma özelliklerine ait görüntüler.

\section{Teşekkür}

Bu çalışma Van Yüzüncü Yıl Üniversitesi, Bilimsel Araştırma Projeleri Başkanlığı tarafından FBA-2017-5847 nolu proje olarak desteklenmiştir.

\section{Kaynakça}

Alkan, G., Seferoğlu, G.H., Tekintaş, \& F.E., Ertan, E. (2014). Aydın ekolojisindeki bazı erik anaç- çeşit kombinasyonlarında klorofil miktarı ve yoğunluklarının belirlenmesi. Adnan Menderes Üniversitesi, Ziraat Fakültesi Dergisi, 11(1), 1-10.

Aras, S., \& Eşitken, A. (2019). Responses of apple plants to salinity stress. Yüzüncü Yıl Üniversitesi Tartm Bilimleri Dergisi, 29(2), 253-257 . DOI: 10.29133/yyutbd.494677.

Arminian, R., Mohammadi, S., Hoshmand, S.A., \& Khodambashi, M. (2010). The genetic analysis of stomatal frequency and size, stomatal conductance, photosynthetic rate and yield in wheat (Triticum aestivum L.) using substitution lines series. Wheat Information Service, 110, 25-34.

Atik, F., \& Dardeniz, A. (2018). Yalova İncisi Üzüm çeşidinde farklı taç yönetimi uygulamalarının yaprakların stoma özellikleri üzerine etkileri. ÇOMÜ, Ziraat Fakültesi Dergisi 6 (özel sayl), 3337.

Bekişli, İ.M. (2014). Harran Ovası koşullarında yetiştirilen bazı asına çeşitleri ile Amerikan asma anaçlarının yaprak ve stoma özelliklerinin belirlenmesi. (yüksek lisans tezi), Harran Üniversitesi, Fen Bilimleri Enstitüsü, Şanlıurfa, Türkiye.

Boselli, M., \& Scienza, A. (1983). Effects of potassium fertilization on density and morphological characteristics of stomata in grapevines. Vignevini (Bologna), 10 (1-2), 27-32. 
Curran, P.J, Dungan, J., \& Gholz, H.L. (1990). Exploring the reletionship between reflectance red edge and chlorophyll content in slash pine. Tree Physiology. 7(1-2-3-4), 33-48.

Çağlar, S., Sütyemez, M., \& Bayazıt, S. (2004). Seçilmiş bazı ceviz (Juglans regia) tiplerinin stoma yoğunlukları. Akdeniz Üniversitesi Ziraat Fakültesi Dergisi, 17 (2), 169-174.

Çeliktopuz, E., Kapur, B., Sarıdaş, M., \& Paydaş Kargı, S. (2018). Determining the yield and morphophysiological responses of 'fortuna' strawberry cv. of using different irrigation levels with biostimulant application. Yüzüncü Yll Üniversitesi Tarım Bilimleri Dergisi, 28(4), 368-374. DOI: 10.29133/yyutbd.426079.

Dardeniz, A., Şeker, M., Killi, D., Gündoğdu, M.A., Sakaldaş, M., \& Dinç, S. (2012). Sofralık üzüm çeşitlerinin yapraklarındaki klorofil miktarının boğumlar bazındaki dönemsel değişiminin belirlenmesi. Uluslararası Tarım, Gıda ve Gastronomi Kongresi, 15-19 Şubat 2012, Antalya.

During, H. (1980). Stomatafrequenz bei Blattem von Vitis-Arten und -Sorten. Vitis, 19, 91-98.

Durmaz, N.E. (2014). Asma yapraklarında stoma yoğunluğunun saptanmasinda saydamlaştırma ve kalıp alma yöntemlerinin karşılaştırllması. (yüksek lisans tezi), Namık Kemal Üniversitesi, Fen Bilimleri Enstitüsü, Tekirdağ, Türkiye.

Düzenli, S., \& Ergenoğlu, F. (1988). Yüksek terbiye sisteminde değiş̧ik şekiller verilmiş farkl anaçlar üzerine aşılı kültür çeşitlerinde stoma dağıllımlarının araştırılması. Türkiye III. Bağcılık Sempozyumu Bildiri Özetleri.

Erez, M.E., Fidan, M., Pınar, S.M., İnal, B., Kaya, Y., Altıntaş, S. (2017). Siirt ilinde yetiştirilen bazı üzüm çeşitlerinin tanımlanması ve kalite değerlerinin belirlenmesi. Türkiye Tarımsal Araştırmalar Dergisi, 4(1), 31-42.

Eriş, A., \& Soylu, A. (1990). Stomatal density in various Turkish grape cultivars. Vitis, Special Issue, 382-389.

Gargın, S. (2009). Eğirdir/Isparta koşullarında bazı üzüm çeşitlerinin stoma yoğunluklarının belirlenmesi. 7. Türkiye Bağcılık ve Teknolojileri Sempozyumu. 5-9 Ekim, Manisa.

Gargın, S. (2011). Băgcılıkta kullanılan farklı Amerikan asma anaçlarının yaprak klorofil yoğunluklarının (SPAD) belirlenmesi. I. Ali Numan Kıraç Tarım Kongresi ve Fuarı. 27-30 Nisan, Eskişehir.

Gargın, S., \& Göktaş, A. (2011). Farklı üzümsü meyve türlerinde yaprak klorofil miktarlarının belirlenmesi. GAP VI. Tarım Kongresi, 9-12 Mayıs, Şanlıurfa.

Gökbayrak, Z., Dardeniz, A., \& Bal, M. (2008). Stomatal density adaptation of grapevine to windy conditions. Trakia Journal of Sciences, 6 (1), 18-22.

Ilgın, M., \& Çağlar, S. (2009). Comparison of leaf stomatal features in some local and foreign apricot (Prunus armeniaca L.) genotypes. African Journal of Biotechnology. 8 (6), 1074-1077.

Iotsova-Baurenska, N. (1975). Stomatal numbers and size in Juglans regia in relation to ecological conditions. Fitologiya, l, 19-24.

İşçi, B., Altındişli, A., Kaçar, E. (2015). Farklı anaçlar üzerine aşılı farklı üzüm çeşitlerinde stoma dağılımı üzerine araştırmalar. ÇOMÜ, Ziraat Fakültesi Dergisi, 3(1), 35-39.

Kaçar, B., Katkat, V., \& Öztürk, Ş. (2006). Bitki Fizyolojisi. Nobel Yayın No:848, 562s, Ankara.

Kara, S., \& Özeker, E. (1999). Farklı anaçlar üzerinde aşılı yuvarlak çekirdeksiz üzüm çeşidinin yaprak özellikleri ve stoma dağılımı üzerinde araştırmalar. Anadolu J. of AAR, 9 (1), 76-85.

Kutbay, H.G., \& Kılınç, M. (1992). Bazı bitkilerdeki klorofil a ve klorofil b içeriklerinin mevsimsel değişimi. F.Ü.XI. Ulusal Biyoloji Kongresi, 24-27 Haziran, Elazığ.

Küçükyumuk, C., Sarısu, H., Yıldız, H., Kaçal, E., \& Koçal, H. (2015). Farklı anaçlar üzerine aşılı 0900 ziraat kiraz çeşidinde su stresinin bazı vejetatif gelişim parametrelerine etkisi. Yüzüncü Yll Üniversitesi Tarım Bilimleri Dergisi, 25(2), 180-192 . DOI: 10.29133/yyutbd.236404.

Lichtenthaller. H.K. (1987). Chlorophylls and carotenoids: Pigments of photosynthetic biomembranes. Methods in Enzymology, 148, 350- 382.

Loveys, B.R., \& Kriedemann, P.E. (1973). Rapid changes in abcisic acid-like inhibitors following alterations in vine low water potential. Physiol. Plant., 28, 476-479.

Marasalı, B., \& Aktekin, A. (2003). Sulanan ve sulanmayan bağ koşullarında yetiştirilen üzüm çeşitlerinde stoma sayısının karşılaştırılması. Tarım Bilimleri Dergisi, 9(3), 370-372.

Marschner, P. (1995). Marschner's Mineral Nutrition of Higher Plant (Special Publications of the Society for General Microbiology). Second Edition. Academic Press. 
Misirl1, A., \& Aksoy, U. (1994). A study on the leaf and stomatal properties of sar1lop fig variety. Ege ÜniversitesiZiraat Fakültesi Dergisi, 31, 57-63.

Muradoğlu, F., Gündoğdu, M. (2011). Stomata size and frequency in some walnut (Juglans regia) cultivars. International Journal of Agriculture and Biology, 13, 1011-1015.

Ohsuni, A., Kanemura, T., Homma, K., Horie, T., \& Shiraiwa, T. (2007). Genotypic variation of stomatal conductance in relation to stomatal density and length in rice (Oryza sativa L.). Plant Production Science, 10, 322-328.

Penuelas, J., Filella, I., \& Gamon, J.A. (1995). Assessment of photosynthetic radiation-use efficiency with spectral reflectance. New Phytologist, 131(3), 291-296.

Porro, D., Bertamini, M., Dorigatti, C., Stefanini, M., \& Ceschini, A. (2002). SPAD for the diagnosis of the nutritional status of vine. Hort. Abst.. 72(4), 3253.

Rana, H.S., \& Chadha, T.R., (1990). Relationship Between Stomatal Density and Vigour in Clones of Some Prunus Species. XXIII. International Hort. Cong. Firenze (Italy) Abst. of Contributed Papers. No. 1232.

Rogiers, S.Y, Hardie, W.J, \& Smith, J.P. (2011). Stomatal density of grapevine leaves (Vitis vinifera L.) responds to soil temperature and atmospheric carbon dioxide. Australian Journal of Grape and Wine Research, 17, 147-152.

Ruehl, E., \& Imgraben, H. (1985). Influence of nitrogen supply on the number of stomata and the structure of leaves of grapevines (Vitis vinifera L.). Wein-Wissenschaft, Wiesbaden,40, 160171.

Sarwar, A.K.M., Golam Abdul Karim, A., \& Masud Rana S.M.A. (2013). Influence of stomatal characteristics on yield and yield attributes of rice. Journal of Bangladesh Agricultural University, 11(1), 47-52.

Sekera, D. (1983). The effect of fingicides and fungicide combinations on grape leaf stomata size and aperture. Vinohrad (Bratislava), 21, 29-31.

Tetik, Ç., \& Dardeniz, A. (2016) Sofralık üzüm çeşitlerinde farklı boğumlardaki yaprakların farklı dönemlerdeki stoma yoğunluk ve büyüklüklerinin belirlenmesi. ÇOMÜ, Ziraat Fakültesi Dergisi, 4 (2), 125-138.

Tompa, B., Kozma, P., \& Polyak, D. (1976). Effect of nutrient treatment as to formation of stomata on vine leaves. Kertesz. Egyet. Koezlemen. (Budapest) ,39, 395-407.

Uyak, C., Keskin, N., Doğan, A., Şensoy Gazioğlu, R.İ., \& Başdinç, A. (2016). Van ekolojisinde yetişen bazı üzüm çeşitlerinin stoma yoğunlukları ve klorofil miktarlarının belirlenmesi. Bahçe, 45 (özel sayl), 738-742.

Withan, F.H, Blayedes, D.F., \& Devlin. R.M. (1971). Experiments in Plant Physiology. Van Nostrand Reinhold Co., (55-58), New York.

Yentür, S. (1984). Bitki Anatomisi. İstanbul Üniversitesi, Fen Fakültesi Yayınları İstanbul, No: 191.

Yousufzai, M.N.K., Siddiqui, K.A., \& Soomro, A.Q. (2009). Flag leaf stomatal frequency and its interrelationship with yield and yield componcnts in wheat (Triticum aestivum L.). Pakistan Journal of Botany, 41, 663-666. 